\title{
EDUCAÇÃO PARA MULHERES: ANÁLISE HISTÓRICA DOS ENSINAMENTOS DE ECONOMIA DOMÉSTICA NO BRASIL
}

\author{
José Carlos do Amaral Junior \\ Universidade Federal de Viçosa (UFV)
}

\section{RESUMO}

A economia doméstica foi introduzida no Brasil em 1909, cuja origem é datada da necessidade de garantir a sobrevivência da família nuclear pós Revolução Industrial. Dessa forma, a economia doméstica foi criada como uma forma de "educação para o lar" para as mulheres, em sintonia com o modelo de família da época que estava fundada na divisão sexual do trabalho. $\mathrm{O}$ objetivo deste trabalho foi analisar a trajetória histórica do ensino de economia doméstica no Brasil desde sua criação até os dias atuais. Pôde-se perceber que o contexto social e histórico de criação do curso no Brasil priorizava a mulher como responsável pela casa e pelos filhos, enquanto o homem era responsável pela vida pública. Historicamente, com a mudança no cenário econômico e político, o curso superior de Economia Doméstica passou a não atender a realidade social em que estava enquadrado e dessa forma iniciou-se um processo de reestruturação de seu conteúdo. O que pode ser visto hoje no ensino de economia doméstica no Brasil é a existência de novos e velhos discursos, em que a necessidade constante que esta área de ensino tem de se adaptar às novas demandas sociais e produtivas coexistem com os fortes vestígios da trajetória histórica da criação do curso.

Palavras-chave: Economia Doméstica; Gênero; Educação.

\section{EDUCATION FOR WOMEN: HISTORICAL ANALYSIS OF THE TEACHINGS OF HOME ECONOMICS IN BRAZIL}

\begin{abstract}
The household economy introduced in Brazil in 1909, whose origin dates back to the need to ensure the survival of the nuclear family after the Industrial Revolution. Thus, the home economics was created as a form of "education for the home" for women, in line with the family model of the time it was founded on the sexual division of labor. The objective of this study was to analyze the historical trajectory of teaching home economics in Brazil since its inception to the present day. Could notice that the social and historical context of creating the course in Brazil prioritized women as responsible for the house and children while the man was responsible for public life. Historically, with the change in economic and political scenario, the Home Economics Historically, the change in economic and political scenario, the degree in home economics did not meet the social reality in which it was framed and thus began a restructuring process of its content. What can be seen today in the teaching of home economics in Brazil is the existence of new and old speeches, where the constant need that this area of education has to adapt to new social and productive demands co-exist with strong traces of the historical trajectory the implementation of the course.
\end{abstract}

Keywords: Home Economics; Gender; Education. 


\section{Uma breve contextualização}

Os estudos atuais envolvendo as mulheres versam sobre os mais distintos temas, dentre os quais ganham considerável destaque aqueles que tratam de questões étnicas e raciais, divisão sexual do trabalho e violência contra a mulher. Há também, aqueles estudos que se preocupam em trazer a categoria de análise em questão para outros campos, como a ciência e a história.

Após as reivindicações do movimento feminista, que ganharam força na década de 70, as conquistas das mulheres frente à sociedade foram muitas, mas ainda estão longe de chegar ao fim. As estatísticas demonstram de forma bastante contundente que as mulheres ganharam espaço tanto no mercado de trabalho quanto no acesso ao ensino superior, mas tais conquistas não demonstram de fato a realidade dos novos problemas que se formam dadas as novas condições.

O acesso ao ensino superior, em especial, chama a atenção. Apesar das mulheres apresentarem um número cada vez maior de ingressas nos cursos de nível superior, alguns estudos, como o desenvolvido por Burschini e Lombardi (2002) demonstram que ainda assim este acesso possui características peculiares, algumas das quais que reforçam a divisão sexual do trabalho. Trata-se aqui do conceito de divisão sexual adotado por Hirata e Kergoat (2007) que considera dois aspectos principais: (1) os indicadores para medir a igualdade entre homens e mulheres, tanto no mercado de trabalho quanto na execução das atividades domésticas; e (2) a abordagem sistemática envolvendo tais desigualdades. Dessa forma, a análise aqui adotada procura enfatizar tais aspectos, considerando também três princípios: separação, hierarquia e distanciamento. Ao se verificar o aumento da inserção das mulheres no ensino superior, tem-se a ideia de que há a promoção da igualdade com os homens, quando na verdade o processo observado é o constante distanciamento (HIRATA e KELGOAT, 2007). Este conceito chave é abordado para demonstrar que não são as comparações entre homens e mulheres que mostram de forma eficiente à divisão sexual do trabalho e sim o distanciamento constante entre ambos. No caso do ensino superior, a criação de cursos especificamente "para mulheres" promoveria esta falsa inclusão na vida pública e um real distanciamento entre os mundos "masculino" e "feminino". Dentre tais cursos, estão aqueles ligados à educação, enfermagem, serviço social, dentre outros. Em especial atenção, o curso de Economia Doméstica, ainda hoje oferecido por cinco universidades públicas no país merece destaque, por ter sido criado e ainda permanecer como campo de conhecimento maioritariamente "feminino" e atrelado ao "mundo doméstico".

Dessa forma, este trabalho procura enfatizar a trajetória histórica dos ensinamentos de economia doméstica no Brasil, demonstrando como educação e o ideal de mulher se articulam neste processo e mantêm efetiva uma gênese de divisão sexual do trabalho que perdura e se reproduz ainda nos dias atuais, sobretudo considerando-se a profissão do Economista Doméstico. Para tal, foi elaborada uma análise de artigos e documentos que permitem traçar de forma geral a trajetória da economia doméstica no Brasil e sua situação nos dias atuais.

\section{A família em crise: o surgimento da economia doméstica}

Antes de prosseguir com a discussão, é preciso delimitar o que se entende como economia doméstica, visto que há duas abordagens principais da temática em uso nos dias atuais. A primeira, diz respeito à "economia do lar", uma economia de cunho generalista, 
popular, habitando o senso comum e sendo praticada por todos na vida cotidiana (TIRIBA, 2004, 2007; HIRATA e KERGOAT, 1994; WEBER, 2006; PIZAIA et al. 2005).

A segunda linha reconhece a economia doméstica como campo de atuação profissional, para o qual se necessita um profissional de formação específica - o economista doméstico. Vale ressaltar que as duas abordagens não estão totalmente separadas e que a segunda surge segundo a filosofia empregada pelos defensores da primeira. É justamente no limiar existente entre as duas abordagens que foca-se a análise do presente estudo, e que se encontra a riqueza da discussão pertinente.

A primeira abordagem, ligada ao senso comum, começou a surgir no início do século XX com a industrialização tardia do Brasil. Muitas famílias deixaram o campo rumo aos centros urbanos em busca de melhores condições de vida. Esta nova conformação de vida social trouxe impactos importantes para a família, que teve de mandar mulheres e crianças para a produção fabril. Essa crise da família, acompanhada pelo aumento considerado do número de divórcios - já que a lógica individual passou a ser a prevalente - assustou os governantes que acreditavam que a falência da família ocasionaria também a falência da sociedade (OLIVEIRA, 2006).

A solução encontrada para tal problema foi a de proporcionar às famílias a eficácia científica para reger o cotidiano familiar e assim alcançar melhor qualidade de vida, recaindo sobre a escola a responsabilidade social de tais ensinamentos. No entanto, a organização do ensino na época era marcada pela priorização de "ensinos diferentes" para homens e mulheres, o que resultou na aplicação dos ensinamentos de economia doméstica apenas nas escolas femininas, visto que era socialmente consentido que aquelas eras atribuições das mulheres (OLIVEIRA, 2006).

Em 1909 criou-se então a cadeira de economia doméstica pelo Ministério da Agricultura, Indústria e Comércio para os cursos profissionalizantes, com sede no Instituto Profissional Feminino da Capital de São Paulo. No entanto, o curso teve um início conturbado, e somente em 1930 o curso retornou às grades curriculares, sendo que no ano de 1942 o curso foi estendido pela Lei Orgânica do Ensino Secundário a todas as séries dos cursos ginasial, clássico e científico.

Mais tarde, em 1952 o primeiro curso superior baseado na economia doméstica é fundado, pela Escola Superior de Ciências Domésticas na antiga Escola Superior de Agricultura e Veterinária (ESAV) - hoje Universidade Federal de Viçosa (UFV).

\section{Uma ciência para mulheres}

Com a criação do primeiro curso superior de economia doméstica em 1952 em uma escola como a ESAV - na época marcada pela tradição exclusivamente rural - o profissional de economia doméstica foi inicialmente muito bem recebido nas equipes de extensão rural daquele momento histórico. Vale lembrar, que a extensão da época, fortemente assistencialista, era marcada pela presença de profissionais das ciências agrárias, como médicos veterinários e agrônomos, e que a inserção do economista doméstico na equipe extensionista permitiu um trabalho paralelo com a família dos agricultores, enquanto os demais profissionais da equipe de extensão trabalhavam com os agricultores na produção.

O espaço de atuação então estava delimitado: os profissionais de economia doméstica, representados exclusivamente por mulheres trabalhavam apenas com mulheres e crianças, no espaço do lar. Os homens trabalhavam com outros homens, no espaço da produção. 
A própria criação do curso reflete a tendência da época em priorizar certa estrutura familiar nuclear, em que os homens estavam ligados à esfera produtiva e as mulheres à esfera doméstica, sobretudo tendo estes ideais reforços no modelo de educação seguido pela ESAV em questão:

Entretanto, os pressupostos teóricos advindos da matriz norte americana implantada na Escola de Viçosa se mostraram pujantes também na forma como a educação feminina é abordada, prevalecendo o modelo mais tradicionalista em relação à função das mulheres na sociedade. A presença das alunas neste ambiente é requerida como forma de manter a unidade da tradicional família mineira, na medida em que a mulher era vista como a base de sustentação e de reprodução de uma série de ideais e costumes que eram necessários ao fazendeiro moderno que a Escola de Viçosa ajudava a desenvolver. (SANTOS, 2006, p.5113)

Desta forma, as disciplinas ofertadas no curso de economia doméstica abordavam temáticas como nutrição, vestuário, decoração, puericultura, educação, arte e recreação. Era uma tentativa de "trazer a casa à escola e levar a escola ao lar" (LOURO, 1987 apud SANTOS, 2006, p.5115). Esta "cientificidade do doméstico" é ainda hoje relatada por professoras que estudaram segundo os moldes da Escola Superior de Ciências Domésticas e relatam, por exemplo a tentativa de trazer as contribuições tayloristas à atividades cotidianas, como o controle cronometrado do preparo de um bolo.

Assim, instalou-se o primeiro curso superior de economia doméstica no Brasil, seguindo moldes de uma estrutura familiar nuclear americana e pregando o status quo de um "lugar feminino" na família e na sociedade. Os primeiros anos do curso tiveram a contribuição da americana Anita Dikson e da americana naturalizada brasileira Sônia da Silva (Ilustração 1).
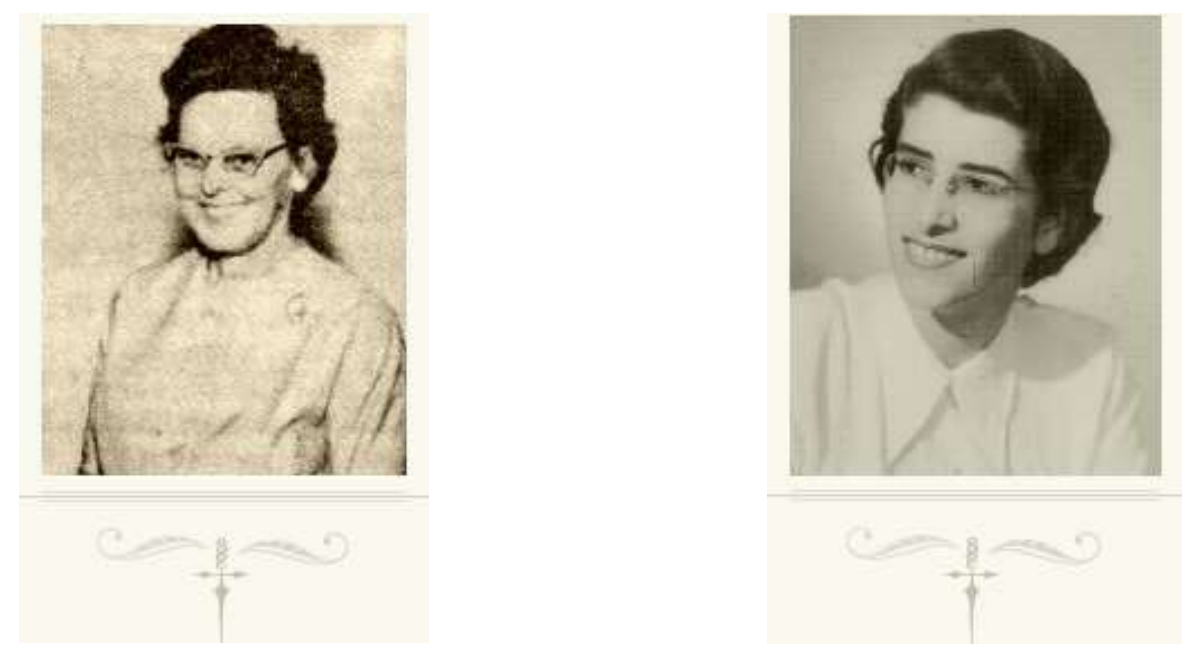

Ilustração 1 - (da esquerda para a direita) Anita Dikson: Americana nascida em Missouri, que ajuda a criar em 1952 a Escola Superior de Ciências Domésticas da ESAV. Lecionava as disciplinas de Decoração do Lar, Nutrição, Ciências Físicas e Naturais, Preparo de Alimentos e Metodologia. Sônia da Silva: Nascida em New York e naturalizada brasileira, em 1956 integra o corpo docente do curso de Ciências Domésticas. Foi a primeira brasileira a obter o título de Ph.D na história da Economia Doméstica no Brasil.

Fonte: http://www.personagens.ufv.br 


\section{Efetivação de um ideal de família em um país agrário: o crescimento e declínio das escolas de economia doméstica}

A partir da criação do curso de Ciências Domésticas na ESAV, observou-se o significativo aumento da instalação de cursos de economia doméstica no Brasil, atraídos, sobretudo, pela condição agrária do país em que o profissional de economia doméstica era muito bem recebido nas equipes extensionistas e em trabalhos com educação no campo. A abertura do curso de licenciatura em economia doméstica também facilitou a ampliação da oferta, visto que a educação primária passou também a ser o foco dos ensinamentos em economia doméstica. O curso também representava de forma geral uma das poucas possibilidades da época da inserção da mulher no ensino superior e no mercado de trabalho, que se dava basicamente em cursos que estavam ligados à "imagem de mulher dócil" (SANTOS, 2006, p.5113) e cursos de reduto "exclusivamente femininos" (BRUSCHINI e LOMBARDI, 2002, p.96)

Dessa forma, acompanhando o crescimento da área no país, a Lei $n^{\circ} 7.387$ de 21 de outubro de 1985 legaliza a profissão de Economista Doméstico como aquele profissional que possui bacharelado ou licenciatura nos cursos de Ciências Domésticas, Economia Doméstica (nome modificado na década de 70 do curso de Ciências Domésticas), Home Economics ou que comprove o trabalho com economia doméstica em pelo menos cinco anos. A referida Lei também reconhece a criação do Conselho de Economia Doméstica e as Competências do Economista Doméstico, a constar:

I - planejar, elaborar, programar, implantar, dirigir, coordenar, orientar, controlar, supervisionar, executar, analisar e auxiliar estudos trabalhos, programas, planos, projetos e pesquisas em economia doméstica e educação familiar ou concernentes ao atendimento das necessidades básicas da família e outros grupos, na comunidade, nas instituições públicas e privadas;

II - planejar, elaborar, implantar, dirigir, coordenar, orientar, controlar, supervisionar, executar, analisar e avaliar estudos, trabalhos, programas, planos, projetos e pesquisas de educação e orientação do consumidor para aquisição e uso de bens de consumo e serviços utilizados pela família e outros grupos nas instituições públicas e privadas.

(Lei $\mathrm{n}^{\circ} 7.387$ de 21 de outubro de 1985, Art. $2^{\circ}$ )

É possível notar que a aprovação da Lei reflete um momento histórico em que, influenciadas pelo movimento feminista da década de 70, as profissionais de economia doméstica buscavam o distanciamento do doméstico, e procuravam ocupar espaços no setor público e privado da produção. No entanto, a ruptura com a trajetória histórica do curso não é totalmente possível e o que se vê é uma tentativa de adaptação das raízes curriculares da economia doméstica para a formação de um profissional que atue além do ambiente doméstico.

Todo o conhecimento desenvolvido historicamente pelos cursos de economia doméstica no país passa então por uma fase de "adaptação" que procura levar os eixos básicos sobre os quais o curso se consolidou - habitação e decoração, alimentação e nutrição, vestuário e têxteis, economia familiar, desenvolvimento humano e extensão rural - para o mundo da produção no sentido capitalista do termo.

Em contrapartida, como resultado da nova configuração econômica e também da influência direta dos movimentos feministas da década de 70, o Brasil presenciou uma 
considerada diminuição dos cursos de economia doméstica no país. Esta diminuição reflete a entrada de mulheres em outros cursos de nível superior - embora a maior porcentagem ainda esteja concentrada nas ciências sociais aplicadas (BRUSCHINI e LOMBARDI, 2002) - e a negação do doméstico como espaço feminino, influência direta dos estudos e debates feministas. Em portarias publicadas no Diário Oficial da União no ano de 1986, eram reconhecidos no Brasil 11 cursos superiores de Economia Doméstica, dos quais atualmente apenas cinco ainda estão em funcionamento.

\section{Economia Doméstica nos dias atuais: rompendo com as raízes históricas?}

Como demonstrado até o momento, o curso de Economia Doméstica foi criado segundo o modelo predominante de família de uma época, e fiel a este modelo, tinha como principal foco as mulheres e assim prepará-las para a melhor administração de seus lares, o que englobava a administração de recursos familiares, a decoração e asseio da casa, a conservação e confecção do vestuário, o cuidado e educação dos filhos e o manejo, higiene, conservação e preparo dos alimentos. O curso foi implantado no Brasil segundo os moldes da Home Economics americana, e seguiu o modelo teórico familiar rígido correspondente a divisão sexual do trabalho nos EUA.

O Brasil, até então predominantemente agrário, recebeu bem o curso de Economia Doméstica, com ênfase especial para aquelas instituições que seguiam os moldes agrários de ensino, onde ainda predominava um ideal de família nuclear. No entanto, com a modificação do contexto econômico do país e a contribuição do movimento feminista dos anos 70, muitos dos cursos de bacharelado e licenciatura em Economia Doméstica não resistiram ao passar do tempo. Os profissionais responsáveis pelos cursos que permaneceram, buscaram intensamente em meados da década de 80 a identidade para o curso, com o reconhecimento da profissão, a criação dos Conselhos Regionais e Federal e o reconhecimento dos cursos daquelas faculdades e universidades que ainda ofereciam a formação em Economia Doméstica - como se pode ver em um conjunto de portarias lançadas entre os anos de 1986 e 1991. Também buscaram romper com o caráter histórico do curso, que basicamente estava focado na formação de boas "administradoras do lar", na medida em que se empenharam em ter reconhecida a atuação do Economista Doméstico em empresas públicas e privadas. É neste contexto também que a Revista Brasileira de Economia Doméstica - OIKOS é lançada, possuindo caráter exclusivamente científico.

Alguns discursos acadêmicos revelam que este foi um movimento bem sucedido e que o profissional de Economia Doméstica tornou-se "indispensável para a manutenção de qualidade de vida das famílias" (OLIVEIRA, 2006, p.85). Por outro lado, em carta endereçada ao Ministro da Educação em 2010, a Secretária de Educação Superior Maria Paula Dallari Bucci revela que o curso teve sua importância social e histórica, mas que está em decadência, e que seu conteúdo não condiz mais com as exigências e demandas da sociedade, sendo que os cinco cursos existentes hoje no país somam menos de mil alunos e tendem à extinção. Longe de julgar os discursos supracitados, este trabalho utiliza-os como pano de fundo para uma análise mais detalhada do ideal de mulher presente no ensino da profissão, sobretudo segundo sua trajetória histórica, para analisar as condições gerais dos cursos ofertados hoje e se, definitivamente, estes cursos romperam com as condições que foram responsáveis por sua criação e ampliação ou se, por continuarem na reprodução destes ideais, estão realmente fadados à extinção.

Para tal, foi realizada uma análise das grades curriculares dos cinco cursos oferecidos na modalidade bacharelado em Economia Doméstica, pelas instituições: 
Universidade Federal de Viçosa (UFV), Universidade Federal Rural do Rio de Janeiro (UFRRJ), Universidade Federal do Ceará (UFC), Universidade Federal Rural de Pernambuco (UFRPE) e Universidade Estadual do Oeste do Paraná (UNIOESTE).

As grades curriculares são constituídas de disciplinas obrigatórias e optativas. $\mathrm{O}$ número de estudantes ingressantes por ano varia de 40 a 80 por instituição. A duração média do curso é de quatro anos, ou oito períodos. A única universidade que ainda oferece a modalidade licenciatura é a UFRRJ, mas para este trabalho somente foram analisadas as grades curriculares dos cursos de bacharelado.

De início pode-se notar a prevalência de instituições de tradições fortemente agrárias, cujo curso de Economia Doméstica foi importante nas décadas de 50/60. Também é possível notar que a maioria das instituições que ainda ofertam o curso estão localizadas em cidades do interior dos estados. Estas características são importantes porque podem refletir até certo ponto as razões pelas quais as instituições ainda mantêm os cursos em funcionamento.

O primeiro curso a ser fundado no Brasil ainda está em funcionamento, que hoje corresponde ao bacharelado em Economia Doméstica pela Universidade Federal de Viçosa. Outro aspecto importante é o de que a UFV é a única instituição que possui o Programa de Pós-Graduação em Economia Doméstica, com área de concentração em Economia Familiar.

Como as grades curriculares priorizam uma formação generalista e multidisciplinar, estas são compostas por disciplinas de diversas áreas como a psicologia, antropologia, química, matemática, educação, nutrição, dentre outras. Desta forma, priorizaram-se para esta análise aquelas disciplinas próprias do curso, que são também aquelas que apresentam algum caráter da trajetória histórica da Economia Doméstica no Brasil.

As grades curriculares das diferentes instituições apresentam certo padrão geral com relação às disciplinas que compõem a formação específica dos estudantes. Estas disciplinas resumidamente são: economia familiar, têxteis, estudo da família, introdução à economia doméstica, modelagem e confecção do vestuário, têxteis e vestuário, planejamento de interiores, conservação têxtil e lavanderia, economia e administração familiar, administração de recursos na família, dentre outras. No entanto, o foco e escopo geral de cada matriz curricular são diferenciados, de acordo com as demandas regionais do profissional e a trajetória histórica e social do curso nas respectivas instituições.

Dessa forma, as disciplinas das cinco diferentes grades podem ser agrupadas em cinco grandes grupos: Alimentação e Nutrição; Habitação e Planejamento de Interiores; Vestuário e Têxteis; Economia Familiar; e Desenvolvimento Humano.

Na Universidade Federal de Viçosa, a área de Desenvolvimento Humano está ainda representada pelo curso de Educação Infantil, criado segundo o desenvolvimento da área dentro da Economia Doméstica. Na verdade, outras duas instituições apresentam fenômenos parecidos: a criação do curso de Turismo e Hotelaria pelos professores da Economia Doméstica na UFRRJ e a criação do curso de Moda pelos professores da Economia Doméstica na UFC. Este movimento, longe de ser encarado como algo somatório ao curso, é entendido como prejudicial, assim como as frutíferas discussões dos profissionais da área sobre como os nutricionistas atrapalham a atuação profissional do economista doméstico ou sobre como a atuação dos assistentes sociais dispensa os economistas domésticos em outros casos (BUCCI, 2010).

Neste sentido, apesar do caráter político atual ser de luta por direitos frente ao mercado de trabalho - lutas representadas pelos Conselhos Regionais e Federal - a realidade das grades curriculares é ambígua frente às condições atuais. 
Basicamente, as grades dos cursos atuais de Economia Doméstica no cenário atual podem ser, do ponto de vista da trajetória histórica do curso, divididas em dois grupos: (1) aquele das disciplinas identitárias frente à nova configuração do mercado de trabalho e (2) aquele das disciplinas enraizadas no modelo de família e de "mulher" concebidos no momento social e histórico da implementação da Economia Doméstica no Brasil.

$\mathrm{O}$ primeiro grupo corresponde às disciplinas na maioria das vezes multi e transdisciplinares. Estas disciplinas apresentam ora caráter técnico, ora caráter teórico, e podem representar uma tentativa de abrir as possibilidades para o profissional de Economia Doméstica frente ao mercado de trabalho. Podem também ser oriundas de demandas de áreas carentes ou ainda uma resposta frente àquelas áreas cuja absorção dos profissionais de economia doméstica tem ocorrido. Longe de tentar elucidar os reais motivos e confirmar as hipóteses aqui formuladas, entende-se que este grupo de disciplinas faz parte do próprio retorno ao longo dos anos que os profissionais de economia doméstica vêm dando acerca de sua formação, e a resposta que os próprios responsáveis pela formação dos economistas domésticos da atualidade têm dado ao mercado.

O segundo grupo, aqui considerado mais crítico, remonta à época em que o curso de economia doméstica foi implantado no Brasil. As disciplinas deste grupo correspondem praticamente às mesmas disciplinas fundadas junto com a Escola Superior de Ciências Domésticas em 1952, apresentadas por Santos (2006). O que se observa na verdade é a manutenção das raízes daquelas disciplinas que foram responsáveis por implantar ideologicamente o primeiro ensino de economia doméstica, no início do século XX. O que se prioriza é a formação de mulheres - porque a maioria absoluta dos ingressos no curso ainda continua representada pelas mulheres, tornando-o um curso de reduto feminino (BRUSCHINI e LOMBARDI, 2002) - com noções de decoração, alimentação, higiene, conservação e produção do vestuário, administração de recursos familiares e etc. Estas disciplinas, na maioria das vezes lecionadas por profissionais formados em Economia Doméstica, remontam no campo abstrato a imagem de mulher multitarefa e de uma "ciência do lar".

No entanto, o que se pode observar é uma coexistência entre o velho e o novo discurso. Há em algumas grades curriculares, por exemplo, disciplinas sobre gênero, o que de fato proporciona um cenário curioso sobre como um discurso de gênero pode emergir em um curso cujas raízes de divisão sexual do trabalho - ou se preferir, organização social baseada em na própria distinção de gênero - são tão intensas.

Outro aspecto relevante é o de que a contribuição científica de pesquisadores da área tem sido bastante significativa nas mais variadas temáticas, dentre as quais, a avaliação de políticas públicas, estudos em desenvolvimento infantil, economia familiar, educação do consumidor e relações de gênero.

O que monta este novo cenário do ensino da economia doméstica é essa coexistência entre o velho e o novo, sobretudo na impressão de que existe a economia doméstica de ontem e a economia doméstica de hoje, com outro foco, outra perspectiva, outra abordagem, embora ainda carregue as marcas de sua trajetória histórica.

\section{Palavras finais}

A primeira pergunta que surgiu ao iniciar este estudo foi se poderia um curso, com influências tão evidentes na divisão sexual do trabalho e na organização social segundo gênero, livrar-se do peso do contexto histórico e social no qual foi concebido. 
Remontando esta trajetória, é possível perceber que a pergunta - e a resposta - são mais complexas do que se pode imaginar. Primeiro, pode-se observar que a criação especifica do ensinamento de economia doméstica no país não objetivava em si inaugurar uma área de conhecimento ou um novo campo da pesquisa científica. O que se pretendia era garantir, através da educação feminina, que a família sobrevivesse. No entanto, o próprio percurso deste ensinamento, influenciado pelo contexto internacional, trouxe ao país o primeiro curso superior de Ciências Domésticas.

O contexto social e histórico de como o curso é implantado no Brasil tem evidente importância: a Ciência Doméstica brasileira surge num contexto de uma sociedade fortemente agrária, que remonta um modelo de família cuja divisão sexual do trabalho era fundante, e que encontrou no seu modelo de efetivação importado dos EUA o apoio necessário para a sua legitimação como campo de conhecimento e científico.

Dessa forma, os cursos de Ciências Domésticas, mais tarde chamados de Economia Doméstica, foram implementados em várias universidades, faculdades e centro de ensino no país, representando uma nova oportunidade para a formação superior de mulheres na época, junto com cursos da área da educação e enfermagem.

No entanto, com a mudança do cenário nacional tanto no nível de produção quanto a nível econômico, o mercado de trabalho começou a apresentar uma configuração diversificada que não mais comportava o modelo de formação pregado nos cursos de Economia Doméstica. Somado a isso, a influência do movimento feminista bem como dos debates e trabalhos sobre gênero, remontam aos poucos o cenário da mulher brasileira, para o qual a Economia Doméstica pareceu aos poucos obsoleta.

Este período marca então o início de uma reconfiguração da formação em economia doméstica. Em meados da década de 80, frente a esta nova configuração do cenário nacional, os profissionais de Economia Doméstica e os responsáveis pelos cursos universitários da referida área começaram uma intensa busca - sindical e jurídica - pelo reconhecimento da profissão, das atribuições do economista doméstico, criação dos conselhos regionais e federal e reconhecimento dos cursos vigentes e suas respectivas universidades ofertantes. Nesta época, o número de cursos superiores em Economia Doméstica no Brasil ainda constavam como onze.

Nos dias atuais, com apenas cinco cursos superiores de bacharelado em Economia Doméstica em funcionamento no país e com constantes indagações sobre o futuro dos ensinamentos desta área, o curso ainda apresenta de certa forma as características de um campo de ensino em transformação. E como todo processo de transformação é contínuo e não representa um rompimento total com a condição anterior, acreditando que as barreiras deste processo são tênues, o que se vê na atualidade é uma coexistência da economia doméstica de ontem - fortemente enraizada na divisão sexual do trabalho e no modelo de família predominante na década de 50 - com a economia doméstica de hoje, em busca por seu espaço na nova configuração social e de produção.

Longe de julgar o futuro deste campo de conhecimento, que hoje está representado por um curso de nível superior específico, este trabalho buscou refletir sobre as trajetórias que implementaram a economia doméstica no Brasil e como sua trajetória histórica e social reflete nos ensinos de economia doméstica da atualidade. Dessa forma, foi possível perceber que ainda existem fortes traços do "universo feminino de outrora" convivendo com novos paradigmas do "ser mulher" no ensino superior atual. 


\section{Referências}

BRASIL. Lei n 7.387 de 21 de outubro de 1985. Diário Oficial [da] República Federativa do Brasil, Poder Executivo, Brasília, DF, 22 de out. de 1985.

BRASIL. Lei no 8.042 de 13 de junho de 1990. Diário Oficial [da] República Federativa do Brasil, Poder Executivo, Brasília, DF, 14 de jun. de 1990.

BRASIL. Portaria n 09 de 15-02-91. Diário Oficial [da] República Federativa do Brasil, Poder Executivo, Brasília, DF, 19 de fev. de 1991.

BRASIL. Portaria n ${ }^{\circ} 118$ de 15-08-86. Diário Oficial [da] República Federativa do Brasil, Poder Executivo, Brasília, DF, 22 de ago. de 1986.

BRASIL. Portaria no 169 de 29-10-86. Diário Oficial [da] República Federativa do Brasil, Poder Executivo, Brasília, DF, 10 de nov. de 1986.

BRASIL. Portaria no 182 de 19-11-86. Diário Oficial [da] República Federativa do Brasil, Poder Executivo, Brasília, DF, 27 de nov. de 1986.

BRASIL. Portaria n 91 de 11-09-87. Diário Oficial [da] República Federativa do Brasil, Poder Executivo, Brasília, DF, 15 de mai. de 1987.

BRUSCHINI, C.; LOMBARDI, M. R. Trabalhadoras brasileiras dos anos 90: mais numerosas, mais velhas e mais instruídas. Mulher e Trabalho, v.2, 2002.

BUCCI, M. P. D. Ofício n ${ }^{\circ}$ 82/2010-MEC-SESu/DESUP. Ministério da Educação Secretaria de Educação Superior. Brasília, DF, dezembro de 2010.

HIRATA, H.; KERGOAT, D. A classe operária tem dois sexos. Estudos Feministas, v.2, n. 1/94, p. 93-100, jan./jul. 1994.

HIRATA, H.; KERGOAT, D. Novas configurações da divisão sexual do trabalho. Cadernos de Pesquisa, v.37, n.132, p. 595-609, set./dez. 2007.

OLIVEIRA, A. C. M. Economia Doméstica: origem, desenvolvimento e campo de atuação profissional. VÉRTICES, v.8, n.1/3, jan./dez. 2006.

PIZAIA, M. G.; SOARES, P. C. S.; CAMARA, M. R. G.; CAMPOS, M. F. S. A importância da água na economia doméstica: formas alternativas para um melhor aproveitamento e economia do recurso pelos residentes domiciliares. In: XLIII Congresso da SOBER - “Instituições, Eficiência, Gestão e Contratos no Sistema Agroindustrial”, Ribeirão Preto, julho de 2005.

SANTOS, T. N. E. Arquivo histórico da Universidade Federal de Viçosa: subsídios e perspectivas para a história da educação superior no Brasil do século XX. In: VI Congresso Luso-Brasileiro de História da Educação, comunicações individuais, Uberlândia: Minas Gerais, abril de 2006, p.5108-5116.

TIRIBA, L. Brincando de casinha: fragmentos de economia, cultura e educação. Revista de Educação Pública, Cuiabá, v.16, n.31, p.161-172, mai./ago. 2007.

TIRIBA, L. Ciência econômica e saber popular: reivindicar o "popular" na economia e na educação. In: TIRIBA, Lia e PICANÇO,,Iracy (orgs): Trabalho e Educação: arquitetos, abelhas e outros tecelões da economia popular solidária. Idéias e Letras, p.75102, 2004. 
UNIVERSIDADE ESTADUAL DO OESTE DO PARANÁ. Economia Doméstica estrutura curricular. Disponível em <http://www.unioeste.br/cursos/beltrao/economiadomestica/> acesso em 10 de julho de 2012.

UNIVERSIDADE FEDERAL DE VIÇOSA. Catálogo de Graduação: Economia Doméstica, Registro Escolar, p.148-152, 2012.

UNIVERSIDADE FEDERAL DE VIÇOSA. Personagens e Pioneiros da UFV. Disponível em < http://www.personagens.ufv.br > acesso em 05 de julho de 2012.

UNIVERSIDADE FEDERAL DO CEARÁ. Economia Doméstica - disciplinas. Disponível em < http://www.economiadomestica.ufc.br/disciplinas.html $>$ acesso em $10 \mathrm{de}$ julho de 2012.

UNIVERSIDADE FEDERAL RURAL DE PERNAMBUCO. Pró-Reitoria de Ensino de Graduação: matriz curricular Economia Doméstica, 2010.

UNIVERSIDADE FEDERAL RURAL DO RIO DE JANEIRO. Decanato de Ensino de Graduação - Grade curricular curso Economia Doméstica, 2006.

WEBER, F. Lares de cuidado e linhas de sucessão: algumas indicações etnográficas na França, hoje. MANA, v.12, n.2, p.479-502, 2006. 